\title{
Analysis of the Features for Pop Style Design
}

\author{
Yuyun Wang \\ Heihe University \\ Heihe, China
}

\author{
Hongmei Zhang \\ Shazhou Professional Institute of Technology \\ Zhangjiagang, China
}

\begin{abstract}
Pop style, it is a performance trend in $1960 \mathrm{~s}$ industrial design which to pursue formal alienation and entertainment. It is not confined to the design of consistent form, there is often a lively mix and match a variety of forms, both noble fantasy art and also pursuit popular public taste.
\end{abstract}

Keywords—pop design; style; analysis

\section{INTRODUCTION}

Pop design features can be divided into two categories: explicit and implicit characteristics. The explicit feature for Pop design is mainly in the form of process design, structure and other aspects. The implicit feature for Pope design is performed in the original design of ideological content, themes and so on, they are often implicit in the design work, pop design's implicit feature is characterized in its humane, commercial and other aspects.

\section{FEATURE OF FORM}

One of the most notable features of pop design movement is formalist style. In this style, the artists have great emphasis on the sense of visual impact and formal sense on product design, especially in the product decoration design, but at the same time they also focus on the combination of structural and functional aspects. Pop design emphasizes popular features, dedicated product designed to make daily life more comfortable, more natural, which reflects the characteristics of the material itself. It contained with exaggerated colors and popular decorative to break the old formalism beauty, appears to be simple, or any combination of fantasy; no specification modernist design skills, it is not first consider practicality and functionality factors, but rely on a strong designer subjective opinions and feelings. But precisely because of this popular design is different from modernism, it has the skills and youthful, lively design forms, vibrant colors and unique focus on new ideas in design, which achieves rich colors and bold ideas.

In Sowden's furniture design works, we can see the modernist transformation of transformation from his classic series "armchair" , a large number of curves constituting the main frame of the chair, plus rich color decoration, make daily living appliances with a distinctive artistic features. Kanner Architects studio in its interior design, they use color expression to make people have full of infinite imagination. Pop design does not confined to modernist form but boldly use the form of lines, colors and space to break from the old forms, gradually formed its distinctive popular features.
Pop design advocates to dialogue with tradition, but the design elements of pop art references or not fully follow the principles of classical or classical revivalism, it combined with modern methods of combining classical tradition and modern logo design and decoration, then it formed a post modern classicism. Similarly, although many design patterns and style borrow the popular culture and style, but it is not kitsch culture.

Pop design exhibition with strong local style: a combination of the architectural design and modern technology and it widely used simple materials such as brick, stone, wood, etc., to find forms of traditional villages and brick walls ,even in someplace it processed into a thick part and housing factors to make its obviously unique national style and local flavor. Hand-dyed purple chair is full of primitive style of the original ecosystem modeling. Brief but not simple style is more emotional and rich mapping out mechanical and monotonous lifestyle needs.

\section{FEATURE OF DECONSTRUCTION}

Deconstruction is a term introduced in various fields which has become more diversified academia word, deconstruction in literature refers to the deduction, which indicates the structure of the debate on how to effectively destroy debate positions. World post-structuralist, Western Marxist theory enthusiasts also have their own opinion. They understand the essence of deconstruction is to break the boundaries of the old rules, or express doubt in these difficult concepts. Pop Art and Design use or re-constitute a different design to decompose or use retro genre of art, with its unique style to be popular in the world.

Ferre, as an American designer, in his "History of Design from the Victorian Era to the Present" [3] has described: between ten to forty years of the twentieth century, the consumer fashion a decade ago still dominates today's pattern of consumption. Style on Schroeder house appears on thousands of consumer goods; Cars at 1950s with caudal fin imitate the late World War II missile; 1950s irons imitate the 1930s diesel car front .This retro fashion always occurred around us. The size of the popular clothing trousers bottom is constantly back and forth, from large to small, from small to large to complete a full cycle. Indeed, popular often display as a loop, however, those old style not just blindly repeat, it developed in a gradual trend forward. As previously Ferre said: "Now the generation explore, learn early style patterns and classify them, thereby creating a unique new style of fashion based on their life experience. And it exactly like the copy of old fashion style. "Such a surface or a formal return to the past 
state of mind, there are two main types: one is to find the difference, find new foothold on the old content; the other is a nostalgic, old design presented in a kind of infinite past nostalgia among the re-emergence of the style of the past, when these things are applied again, and formally accepted by the public, they are easy to find consensus in a kind of intimacy.

\section{FEATURES OF ORIGINAL}

Early fifties of the twentieth century, scientific has rapid development, material update rate is accelerating, high-tech, new materials, the shape of the sphere is a sci-fi design trends, pop fashion design in a number of large-scale application of new materials, new process to express these elements. Designers combines curiosity and human exploration and pursuit the space cleverly, the knowledge about outer space being used in a bold design, the endless imagination for the space had became the main inspiration into a construction and internal decoration, so a lot of color and form filled with space atmosphere, smooth lines of home furnishings and appliances have emerged. They create cubes, spheres, cones, cylinders and other physical and geometrical sense of science fiction related products, they use high-tech materials and applications, they use of more plastic and polyester. Simply speaking, Europe's "space program" are to some extent, have a certain impact on the designers' creation in 1960s, the Pope design has characteristics of the times in the design, showing in particular concept of imagination and a strong sense of alternative, abstract, comfort, and so on. Unique rich colors and avant-garde sci-fi type design style has been used on furniture and construction outward, this is a landmark in the history of design.

In the year of 1965, Italian designer Joe Colombo had discussion related to pop design [4], he said: "today is not belong to a single performance by a certain style, but use of different forms of expression: all the skills , thoughts, ideas and inspiration to coexist. "In the description, it expresses the design philosophy of the 1960s. At that time designers are inspired by diverse modernism, but also try to explore a break of the unified standard, seeking the ideal form of pluralism, to show the basic concept of the hearts of fantasy and avant-garde designs. Summing up the appeal with artistic design to express a variety of ideas and concepts in life style, focusing on subjective feelings and the objective world, emphasizing the work of mass production, both on the binding industry and industrial machinery and mechanical social resentment, they believe art should be civilian applied to the mass media.

\section{FEATURE OF HUMANIZATION}

Pop design, more emphasis on humane expression, although Pope designers more opposed to the unified design style ,they emphasis on individual design emotion and artistic expression in the design, but it does not mean to put selfimposed idea among cultural life, they believe excessive emphasis on self artistic attitude will affect the art of public social services. For this reason, the ideal design should reflect the highest state of human thought.
People have different needs in different historical periods due to the progress and development of society, and art design should fully take into account the needs of most people, and show their humanity in their designs. In this regard, there was a representative dinnerware designed by a German designer, this is a set of dinnerware specially designed for the disabled people, in appearance we can not see any difference between the ordinary and cutlery, only when you hold the handle, the user will feel a distinctive sense of balance, easy to use while maintaining the self-esteem of people with disabilities, which shows respect from designer for people with disabilities. It is derived from the humanization features of the design concept.

In boom "Pop" design movement in the late 1960s American design theorist Victor Papanek in his most famous book, "Design for the Real World" put a theoretical point of view of "design purpose" from careful design aspect [4], the point of view plays an important role in promoting development of design for the future. He proposed three design purposes: first, design serves to most people; on the other hand, in the design of not only taking into account the health of people with disabilities should also be taken into account, the final design should also consider how to utilize and protect the limited Earth resources.

Pope design focus on humanity care, this sentence can also be seen as a functionalist. It is a modernist advocated enrich and develop functionalism that is to develop the rational, logical function into both physiological and psychological function. American designer Ploss said: People always think the design has three levels - aesthetic, technical and economic. But more important is "human nature." People-oriented design, of course, pop design is people-oriented, humanism in pop design gradually be understood, and "culture" as the carrier of "people-oriented" , which reflect the sum of creation of material and spiritual wealth. The core of design is people, and all designs are actually created around people's needs. All kinds of demands determined design. American behavioral scientists Maslow divided human needs into five levels from low to high: physiological needs, security needs, social needs, esteem needs and self-realization needs. Maslow said that five levels are gradually rising, only after immediate needs are met, the next level need will occur. Human design from simple to practical, it also contains a variety of the human spirit rising cultural factors, it reflects the increasing demand. As pop design objects, it is to meet the needs of the human spirit, coordination, balance and emotional aspect with no doubt.

\section{FEATURE OF COMMERCIALIZATION}

In the 1960s, the so-called "affluent society" of Western countries, people's consumer attitudes began to change into the novelty and difference direction, which is when the commercial design has been a qualitative change. Design itself, starting with "form follows the market" instead of "form follows function", which is to serve the market. They will produce product based on what the market need, all kinds of design, packaging, advertising are marketing methods. Clearly, it blocks the ideological and exploratory of design itself, while commercial competition becomes the driving force for its development. 
Pop design focus on commercial expression, when it comes to Pop Art, Lichtenstein says: "Pop Art can be considered as two 20th-century art tend product, one from the outside - that is the subject; secondly from inside - that is the beauty [5] "of course, the theme is commercial and it belongs to commercial art, but its contribution is the encouragement and praise to the" substance ". Commercial art is not our moral art, it's just one of the theme, in this sense it is natural, but it is considered the exact opposite direction with the Renaissance and Renaissance art . Artistic life, the disappearance of the difference between art and life, the impact of the concept of hierarchy of traditional art and aesthetics and philosophy of deconstruction, not just resulting from the requirements of art form, but also from historical and changes in society. Pop design is also more life, more closely with commercial contacts. Designed products make people feel more interesting and attractive to consumers, the products full of fun, evocative, disseminate information, extend the product promotion.

With fierce competition in the market (including overall level of consumer are raising) and the development of art itself, especially in the context of post-modernism, commercial design often thought deeply on Social Ethics and resource usage and so on. A good commercial design should have full of fun and entertainment but also please consumers and the market without kitsch ideas and technology. It focuses on the design exploration of artistic qualities, to seek new breakthroughs in order to meet consumer needs and aesthetic taste.

Under the impact of pop design style, more designers pay close attention to the relationship between furniture and consumers 's real life and their application, in the design they use bold artistic creativity, gorgeous colors, exaggeration peculiar external form, modern decoration to emphasis on visual effects, and innovative materials. A variety of popular factors which meet the public psychological demands has been added to pop design, so that makes the pop design become more and more diversification.

\section{REFERENCES}

[1] Liu Dengfeng Pop Art social roots of [J] academia Section 137 .2009.4: 9-11.

[2] Wang Hongyuan Pop road -from Pop Art to Pop Art strategy [D] China Academy of Art. 2006: 10-11.

[3] Bao Shidu Western Modernist art [M] China Youth Publishing House in January 1993 Beijing edition 1: 14-16.

[4] Wang Zhihe, Yu Qizhi, Wang Xiaoxi, Li Dong Dictionary of postmodernism [M] Central Compilation and Translation Press 2005.1: 9-16.

[5] Mao Xulin The postmodernist avant-garde of Pop desidn and its influence [D] Tsinghua University 2012.5: 9-11.

[6] (US) Robert Hughes Art Nouveau shock [M] Liu Pingiun, Wang Qing, Zhang Heyi Translation Shanghai people: 10-15. 